\title{
Consumers of a Special Product/Service Within a Changing Business and Social Environment
}

\author{
Alexandru Trifu \\ University "Petre Andrei" of Iasi, Romania \\ alexandru.trifu@gmail.com
}

\begin{abstract}
We consider that around the Consumer gravitate all the problems concerning any provider (supplyer) or distributor. The actual economic and financial world crisis shown, once more, that the firms have to conceive and develop theirs products and services according to the needs, the preferences and the budgets of the potential consumers. The domain of mobile telephony is the the specific production and service aspect addressed in this paper. Despite the crisis effects, this domain continued its expansion in Romania and not only. The communication is a necessity and the facilities, the devices and the revolutionary new IT technologies are essential in these days for many people, among them the Romanian consumers. The study case is based on the experience of a Romanian company, Vegastel (partner of the corporate entity "O", which has realised remarkable economic and financial results, just by the special attention to the requirements, preferences and financial potential of the clients (individuals or firms). The importance of the domain and its continuing improvement and reshaping entail for the firms in the field, including Vegastel, to permanent adapt the offer and take into account the consumers' feedback, such that to gain profits and to remain sustainable on the market.
\end{abstract}

Keywords: Mobile cells domain, satisfaction, utility, consumers, questionnaires

\section{Methodological Approach}

In this paper, the main methodological instrument in analyzing the consumers behavior, needs and trends, is represented by the questionnaire tool. We agree that is a sensitive enterprise, first of all, due to the a dynamic and developing domain and, secondly, due to the specific kind of customers, desiring to have updated devices for calling, chating, mailing and other activities in different places. The questionnaire used in the present analysis includes 15 open and semi-open questions and a subjective scale for the consumers'attitude intensity. This tool of investigation will show us the preferences and habits of the mobile telephony clients, especially of Orange firm, the " $O$ " corporation. Due to the large number of this firm's clients in Romania, we used 100 questionnaires, i.e. the sample is 100 persons, through authorized Orange personel and the partner analyzed, in order to interview consumers and potential clients. The first questions were easy and the last questions needed a little bit more study. In a sum, 15 questions included in the questionnaires. Therefore, we have as synthesis, the following selected questions and answers received:

1. Do yo use Orange network services?

a. Yes

b. No

2. Do you know the products and services provided by Orange? a. Yes b. No

5. From the three main services provided by Orange, which is the most important for you?

1. Subscriptions;

2. Prepaid;

3. Internet.
Answers

$88 \%$

$12 \%$

Answers

$84 \%$

$16 \%$

Answers

$26 \%$

$59 \%$

$15 \%$

13. How do you appreciate the quality of mobile phones services provided by Orange, through its partner SC Vegastel SRL?
Very good
good
satisfactory
weak
very weak 


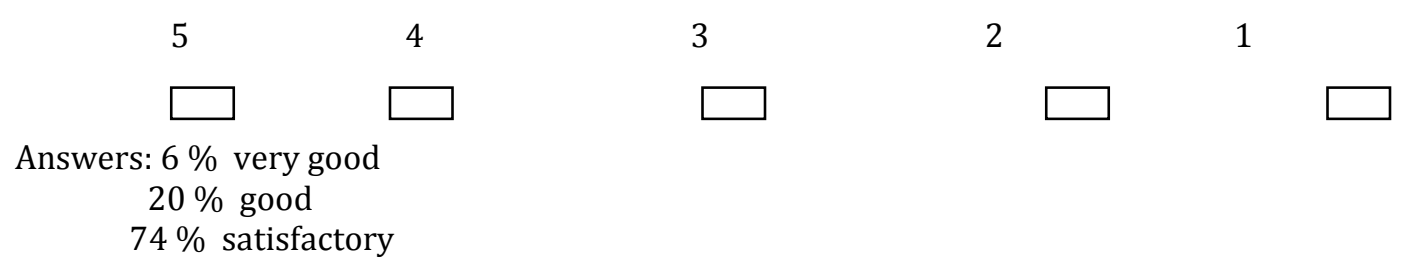

14. On a scale from -5 la +5 indicate your option. Are you considering that the prices of Orange products and services are justified by their quality at SC Vegastel SRL ?

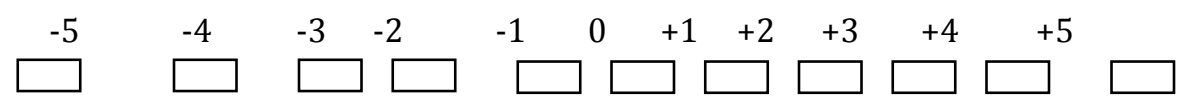

Answers: $41 \times(+5)=205$ the score

$15 \times(+4)=60$ the score

$22 \times(+3)=66$ the score

$22 \times(+2)=44$ the score

TOTAL: $100 \%$ and the score 375

15. Are you satisfied by the diversity of products and services

and by the staff qualification?

1. Yes

Answers

2. No

$74 \%$

3. Relatively

$4 \%$

$22 \%$

\section{The buying decision process}

The purchasing behavior comprises a less widely area and refers specifically to actions taken by the consumer when deciding to buy or not to buy a product. The actual purchase decision is not taken immediately. It appears as the final result of a sequential process having certain duration in time. For most decisions of this nature, people go through a process consisting of five sequences: the awareness of the need, the search for information, the assessment of alternatives, the performance of the purchase and the assessment of the purchase made. The first step is to recognize that there is a need to be met or a task to be solved. The awareness of the need is triggered when finding a discrepancy between the desired state and the status quo. This is experienced as a feeling of lack or a physical or mental discomfort and generates an internal voltage that triggers the decision process. The awareness of the problem can be instant (when one noticed the car or the washing machine is broken) or evolutionary (i.e. when one adopts a new hairdo). Once he is aware of the need, the consumer starts looking into how he might cover or satisfy it. The inner search is to verify existing knowledge about the need in question, and then starts a search for information from external sources (family, friends, colleagues, catalogues, brochures, media, packaging, and so on).

The proportions of the research activity in such a decision-making process depends on individual the characteristics (personality, experience, motivation, education), on the market characteristics (number of possibilities, price range, availability of information) and the situational characteristics (time constraints, financial pressure). A major factor and influence felt on the amplitude of the information search stage is the perceived risk, i.e. the degree of uncertainty about the item to be purchased. It generates caution and concern for the losses that may originate in the wrong choice. After evaluating all alternatives, the buyer can first choose the brand and then the place to buy, but also to choose first the place and then the brand or both at once. Most of the purchases are not well planned ex-ante; most decisions are made in the store, on the spot. The decisions of this type are characterized by spontaneity, emotion and indifference regarding consequences. One of the tasks of the marketer is to increase the possibility of customer satisfaction through both avoiding to create unrealistic expectations and by following his reactions, by taking seriously the customer's suggestions and complaints, by ensuring the quality control of products, by providing information on the use and the post-sale service eventually. The complexity of the decision-making process largely depends on the degree of involvement of the consumer, an involvement resulting from the importance or relevance assigned to the product choice in a given situation. The involvement increases when the individual 
attaches to the product a high symbolic or personal value, when the product concerns his/her fundamental values as well as when the act of purchase is perceived as having a high degree of risk. The higher the involvement the more complex the problem-solving process is. When the involvement is minimal, as in the case of buying the usual assortment of bread daily, the decision making process is minimal and it was labeled as a problem solving routine. The extensive problem solving occurs when a high involvement and a comprehensive assessment of a relatively large number of alternatives is required, such as when buying an apartment or car.

\section{The particular case}

Orange Romania is the largest GSM operator in Romania. Until April 2002, Orange has operated under the brand Dialog. In February2006, Orange Romania had over 7.000.000 customers, which indicated a market share of $56.95 \%$. The success of the Orange brand in Romania is due not only to the attractiveness the mobile telephone represents but also to the network quality, offered services and brand. Orange Romania offers each person in Romania the choice to choose between flexible subscription plans, which can be customizable, and PrePay (prepaid) cards. Precisely, we are speaking about a firm, partner with Orange Romania, considered most pliable on the needs and trends of Romanian population (especially the youth one). The main activities of SC Vegastel SRL are trade, providing services, customer advice activities and post-sales activities (service). These are outlined in Table 1.

\section{Table 1: The main activities, products and services of SC Vegastel SRL}

\begin{tabular}{lll}
\hline No. & Type of activity & Products \\
\hline 1 & Trading activity & 1.The actual sales action \\
& & 2.Marketing of mobile phones \\
& 3.Marketing mobile phone accessories \\
& 4.Marketing PrePay (prepaid) cards
\end{tabular}

To support these activities, the company hired dynamic people and initiated training courses in sales. The customer focus is the most important aspect, thus succeeding in the formation of its customers and also in maintaining the highest degree of satisfaction. The trade activity consists of actually selling phones, accessories and prepaid phones. SC Vegastel SRL is trying to loyal its customers by introducing a special price, offering various discounts depending on the services selected by customers. Most phones are sold in the following order: Apple, Nokia, Samsung and LG equally occupy the third place, Siemens, Apple, Blackberry, Sony Ericsson, while other brands such as Motorola, Panasonic, Philips, Sharp have disappeared from the market. The most popular brands are Apple, Nokia, Samsung, LG, considered leaders of value and highlights, beyond quality, reliability, performance, design, interconnection facilities, the provision of complex data transfer and Internet access, as well as a wide range of applications.

The service activity is the strength of the SC Vegastel SRL network of stores. It is large network because it includes a very broad range of services: from subscriptions ending with the conclusion of repair services. The company promoted through specialized staff and services such as booklets and brochures:

- Communication through subscriptions and options tailored to each client;

- Communication via short messages (SMS) and Multimedia Messaging Service (EMS and MMS);

- Ensuring user comfort by enabling services such as: international calls, roaming, access to mobile banking (bank account can access from your mobile phone), book tickets by train, airplane and other means of transport; 
- Possibility of connecting to the Internet with your mobile phone and activate services such as mobile fax and data transfer, mobile Internet access, WAP and Internet, Mobile E-mail, video calls via 3G technology;

Also, we consider that counseling in sales requires more accurate guidance to customer's products and services that fit the profile and needs.

Human resources and the Quality: Human resources in SC Vegastel SRL are the "main engine" in sales activities and counseling. Sales staff, first of all, must be well trained and have the vocation of working with people, be good speakers and good psychologists. The main factor for understanding the demand, the needs of clients, and the utility of products/services is the theory developed by A. Maslow to be fulfilled in practice. Otherwise the company would not exist or would exist at a very low level. This is the relationship of the human resources department of the company selling advice SC Vegastel SRL consumer products and services Orange, but we can relate to human relationships in the same firm that works, as in all organizations the same way as more above.

Table 2 The main indicators of the activity of the firm

\begin{tabular}{llll}
\hline & $\mathbf{2 0 1 1}$ & $\mathbf{2 0 1 2}$ & $\mathbf{2 0 1 3}$ \\
\hline 1. Sales of goods & 75.136 & 162.335 & 237.779 \\
2.Income from Orange subscriptions & 2.520 & 5.644 & 10.499 \\
3.Cost of the sold goods & 62.445 & 139.993 & 229.733 \\
4. Total expenditure, of which: & 3673,56 & 5712,20 & $13.150,20$ \\
- Staff expenditure & 300,20 & 636,50 & $2.462,40$ \\
- Rates and taxes & 472,96 & 889,10 & 3652,2 \\
- Maintenance expenses & 180 & 220 & 640 \\
- Capital expenditure & 2500 & 3600 & 5500 \\
- Financial expenditures & 220,4 & 366,6 & 895,6 \\
5. Accounting profit margin & $11.537,44$ & $22.273,80$ & $5.344,80$ \\
\hline
\end{tabular}

The analysis of data presented in Table 2 shows that during the past three years the company's expanded sales volume increased in 2012 by nearly the double of 2011, but in 2013 it declined, the gross profit in 2013 being approx. 50\% of the value reached in 2012. In spending, they increased from year to year with increasing number of employees and expanding business in several cities of the country (50). These three years have increased in direct proportion to the incomes of the firm.

\section{Results and conclusion}

After data processing and analysis we can draw the following conclusions, based on the results of the questionnaire, precisely on the 5 main questions regarding the firm, the clients, the vending system and the final satisfaction:

The answer to question 1 gets the information that $88 \%$ of the 100 respondents use the services of Orange. It is a very good result considering the fact that not all people have the same access to information and the sample used contains people of all ages and social classes.

Question 2 highlights the fact that out of 100 respondents 64 were aware of Orange services, which means that the other $36 \%$ usually do not use the services or confined to an insignificant part of the services offered by Orange, being well informed about with existing services. Here the decisive SC Vegastel SRL to promote its agency, Orange services and attract potential customers. The interested persons are the mobile telephony segment aged 20-50 years who actually use most Orange services. Especially for this segment SC Vegastel SRL could adapt some deals to attract more customers in this age group by Orange products and services. A very important aspect in the use of mobile telephony, is the financial aspect (the financial situation is better, the more subscriptions will end with several minutes of talk time included by default will spend more money).

Answering question 5, it is observed a clear preference for services rechargeable cards with a percentage of $59 \%$ of all persons participating in the interview, while $26 \%$ prefer subscriptions, and only $15 \%$ use internet services from Orange. Almost half of the subjects stated that an option that includes 50 minutes of national, 
would be very well received, which means that Orange users use subscriptions and cards and calls to other networks than Orange. This would have to be taken into account should be allocated minutes several categories depending on the budget of each category of customer. The bottom line is I would have made and received another questionnaire covering all services and include more detailed questions to identify the best types of customers, depending on the income to be able to develop a more complex offering. Introducing a higher bonus for rechargeable cards worth more than 9 euro is decisive for $35 \%$ of the respondents, $25 \%$ considers it very important, while $20 \%$ think it is important. These figures highlight that if a higher bonus would produce a higher volume of sales with credit cards more, and therefore would make a higher profit partner Orange SC Vegastel SRL.

Last 3 questions emphasizes that $74 \%$ of those surveyed considered satisfactory mobile telephony market, $41 \%$ agreed that the value is justified, and $74 \%$ of the sample population is satisfied with the quality of Orange. Customers will be fully satisfied when they get quality products and services at reasonable prices, leading to existing customer loyalty and improving it by grabbing more customers from other phone networks, and new users. It can be concluded that although there performance in terms of quality of services provided by Orange, they can improve from surveys conducted in different populations. Customers who attend SC Vegastel SRL are a homogeneous group with the same tastes and the same needs, so it is essential for the firm to adapt as identified segments of consumers with the same preferences and family budgets comparable. The expectations with regard to a particular product may be affected by several factors. If Orange products and services to consumers choosing a product may be affected by:

- Some previous experience related to a brand or a product that the consumer determines not to purchase the product, or on the contrary to have been satisfied with the product and want to take some of the same range or brand. This could lead to increased sales of certain brands of mobile phones.

- Advertising, information media, the method of presentation of the goods by sales agents can influence the decision taken by a consumer concerning the choice of a specific product. SC Vegastel SRL tries to guide customers to products that do need them by finding out their needs and directing them according to their budget to product quality and advantageous in terms of value for money.

- The information given by family, friends and acquaintances play a decisive role in the choice of products and services Orange by current and potential customers.

If the customer satisfaction and even cut is expected to exceed, its retention is cut; the customer is not completely satisfied attempting an opportunity to correct this by various methods: replace the product with another more advanced, post-sale service delivery (service) in the best conditions. Under the influence of preferences and wishes of customers, but also under the pressure of competition, products and services are improved, redesigned and adjusted continuously. The increasing quality standards and quality products mean becoming more efficient. In this respect, Vegastel tries to continuously update products appearing on the market in the shortest time so that customers always find the opportunity to purchase the latest products of the mobile market. Customer retention is a major focus of the company's marketing strategy. Currently the client is described as "a true capital" to be managed with maximum efficiency the following reasons:

- the cost of attracting new customers is appreciably higher than maintaining existing ones;

- the fidelity can be maintained only evolving in that direction and consumer preferences, fashion, technology, etc..., indicating the quality of supply and the price level within acceptable parameters while ensuring continuous supply Relating to competition;

- a loyal customer fully satisfied, will result directly or indirectly from other customers;

- a dissatisfied customer is much more than the cost of a lost customer: negative impressions can remove potential customers and so on.

To retain and to loyalty the customers, SC Vegastel SRL uses a complex system: offers free phones in preparing subscriptions, offering customers the opportunity to pay in installments more expensive products, working with several banks so that the client can choose the most convenient credit. The company works with important banks as BRD Groupe Societe Generale, Raiffeisen Bank and Euroline Retail Service. Related services play an important role in business strategy. To be operative in case of failure of mobile phones, Vegastel established a separate department dealing with the activities of mobile repair defects from customers. SC Vegastel SRL, customer loyalty is achieved through human resource management, customer 
relations specialist, available anytime to solve the problems occurring during the use of a product and / or service.

\section{References}

Blythe, J. (1998). Comportamentul Consumatorului -Ed. Teora, Bucureşti.

Boier, R. (1994). Comportamentul Consumatorului (Consumer Behavior)- Ed. Graphix, Iaşi.

Darpy, D. \& Volle, P. (2003). Comportements du consumateur, Dunord, Paris.

Lache, C. (2010). Comportamentul Consumatorilor, Performantica, Iaşi.

Lache, C. (2010). Marketing în turism şi servicii, Performantica, Iaşi.

Howard, J. A. \& Sheth, J. N. (1969). The Theory of Buyer Behavior, John Wiley \& Sons, New York.

Houston, M. J. \& Rothschild, M. L. (1978). Conceptual and Methodological Perspectives in Involvement, Research Frontiers in Marketing, Ed. S. Jain, Chicago.

Kapferer, J. N. \& Laurent, G. (1986). Les profils d'implication- Recherche et aplications en marketing 1,1.

Krugman, H. E. (1967). The measurement of advertising invoement, Public Opinion Quartely, 30.

Ladwein, R. (1999). Le comportament du consommateur et de l' achteur, Ed. Economica, Paris.

Maslow, A. (1954). Motivations and personality, Harper and Row.

Reuchlin, M. (1966). Psychologie, PUF, Paris.

www. anrc.ro

www.orange.ro

www. Wikipedia.com

***data SC Vegastel SRL available 